\title{
When Posture is Controlled, Acute Hypoxia does not Decrease Core Temperature
}

\author{
Kayli Dalton, Viktoria Brautigam,Michae I J. Buono* \\ San Diego State University,San Diego, CA 92182-7251
}

\begin{abstract}
It has been reported that acute hypoxia causes a reduction in core temperature in humans. It was hypothesized that this occurs due to both a decrease in metabolic rate and an increase in skin blood flow. However, other studies have found that core temperature decreases with changes in posture. The methods in previous studies finding hypoxia to decrease core temperature did not control for postural changes. Thus, further examination is warranted to examine the effect of hypo xia on core temperature while controlling for posture change. Ten healthy adults, between the ages of 18 and 45 were recruited to participate. Subjects completed one trial consisting of breathing normo xic air $(20.9 \%)$ for a 2 hour period and hypoxic air for a 1 hour period, while systematically changing posture. During this time core temperature and skin blood flow were recorded every 5 minutes. The results showed that mean core body temperature significantly $(\mathrm{p}<0.05)$ decreased by $0.4^{\circ} \mathrm{C}$ when the subjects transitioned from a standing to lying position. Ho wever, acute hypoxia, which reduced the mean oxygen saturation to $85 \%$, did not significantly affect core temperature. Such results suggest that when posture is controlled, acute hypoxia does not significantly decrease core body temperature. Thus, the results of previous studies that have reported decreases in core temperature with acute hypoxia, but failed to control for posture, need to be questioned.
\end{abstract}

Keywords Posture, Core Temperature, Hypoxia, Skin Blood Flow

\section{Introduction}

Previous studies have reported that core temperature in humans decreases with acute exposure to hypoxia[1, 2]. It was hypothesized that this occurs due to both a decrease in metabolic rate and an increase in skin blood flow[2]. However, other studies have found that core temperature decreases with changes in posture[3]. Posture temperature changes may be related to circulatory readjustments. Specifically, there is an increased return of cool venous blood from the legs to the core upon lying down and on standing there is a decreased return of venous blood and a reduction of heat loss from the legs due to cutaneous vasoconstriction[4]. The methods in previous studies that reported acute hypoxia to decrease core temperature did not control for postural changes. For example, one study found that when oxygen content was progressively lowered, body temperature also decreased; however, during this time, subjects went from a standing position to a lying position[1]. Thus, further study on the effect of acute hypoxia on core temperature while controlling for posture is warranted. It was hypothesized that when posture is controlled, acute hypoxia will not significantly affect core body temperature.

* Corresponding author:

mbuono@mail.sdsu.edu (Michael J. Buono)

Published online at http:/journal.sapub.org/als

Copyright (C) 2012 Scientific \& Academic Publishing. All Rights Reserved

\section{Materials and Methods}

\subsection{Subjects}

Tenhealthy subjects ( 5 males, 5 females) between the ages of 18 and 45 years were asked to report to the lab on one occasion. Female subjects wererequired to take a urine pregnancy test prior to participation to ensure that they were not pregnant. All 10 subjects completed the testing protocol.

\subsection{Selection Criteria and Participation Screening}

The study was approved by the San Diego State University IRB prior to the start of data collection. Before participation, written informed consent was obtained from all volunteers. The consent form was administered in person, explained by an investigator who was present to answer any questions. Subjects were asked if they had experienced altitude sickness (e.g. nausea, vomiting, labored breathing, etc) when they had previously gone to moderate altitudes. If they had, they were excluded from participation in the study.

\subsection{Subject Involvement}

Subjects reported to the laboratory on one occasion during which they rested in normo xic air for appro ximately 2 hours and in hypoxic air for approximately 1 hour. The a mbient air temperature in the lab during testing was $22-24^{\circ} \mathrm{C}$. Subjects 
wore a clear plastic dome to ad min ister the hypoxic air. The clear plastic dome fit over the subjects' head with plenty of air space to prevent claustrophobia. Since the hypoxic air administration did not obstruct the mouth, subjects were still able to talk and be heard, thus, if they needed to stop the study they did so verbally. As postural changes during data collection affect the data, subjects were asked to urinate before the start of the study. Subjects refrained from caffeine, alcohol, and exercise at least 12 hours before the study and refrained from eating and drinking 3 hours before data collection.

\subsection{Description of Research Design}

Participants completed one trial which consisted of a baseline measure of core temperature while standing for 15 minutes, followed by lying supine until core temperature stabilized, as evidenced by two consecutive readings within $0.01{ }^{\circ} \mathrm{C}$ (approximately $45 \mathrm{~min}$ ). During baseline measures subjects breathed ambient air using a clear plastic dome, which has $20.9 \%$ oxygen. After core temperature stabilized subjects were exposed to hypoxic air for one hour. The concentration of oxygen in the hypoxic air was continually adjusted for each subjectto maintain their hemoglobin oxygen saturation at $85 \%$ which was measured using a pulse-oximeter. Subjects then remained supine for another 30 minutes during which time they breathed $20.9 \%$ oxygen. Lastly, they stood again for 15 minutes. Core temperature was recorded via a rectal probe inserted $10 \mathrm{~cm}$ past the anal sphincter every 5 minutes. Skin blood flow was obtained via laser-Doppler probe (Moor Instruments)attached to the forearm and was recorded every 5 minutes.

\subsection{Statistical Analysis}

A one-way repeated measures analysis of variance was conducted to examine theeffects of posture and hypoxia on core temperature. Significance was set at $\mathrm{p}<0.05$. Post-hocTukey HSD test comparisons were used to find variance between the individual testing environments.

\section{Results}

There were no differences in the responses seen for men and women, thus the data was pooled. As can be seen in Fig. 1 ,a significant effect on core temperature was seen $\left(\mathrm{F}_{4}\right.$, $36=37.41, p<0.01$ ) between the five different testing conditions. Specifically, the mean $( \pm \mathrm{SD})$ initial standing, normoxic core temperature $\left(37.23 \pm 0.38{ }^{\circ} \mathrm{C}\right)$ was significantly different $(\mathrm{p}<0.01)$ from the lying normoxic $\left(36.76 \pm 0.08^{\circ} \mathrm{C}\right)$, ly ing hypoxic $\left(36.63 \pm 0.08^{\circ} \mathrm{C}\right)$, and lying normo xic $\left(36.77 \pm 0.05^{\circ} \mathrm{C}\right)$ conditions. However, there was no significant difference $(p>0.05)$ between the normoxic and hypoxic lying postures despite there being a significant difference in the hemoglobinoxygen saturation (Fig. 2) between the two conditions.

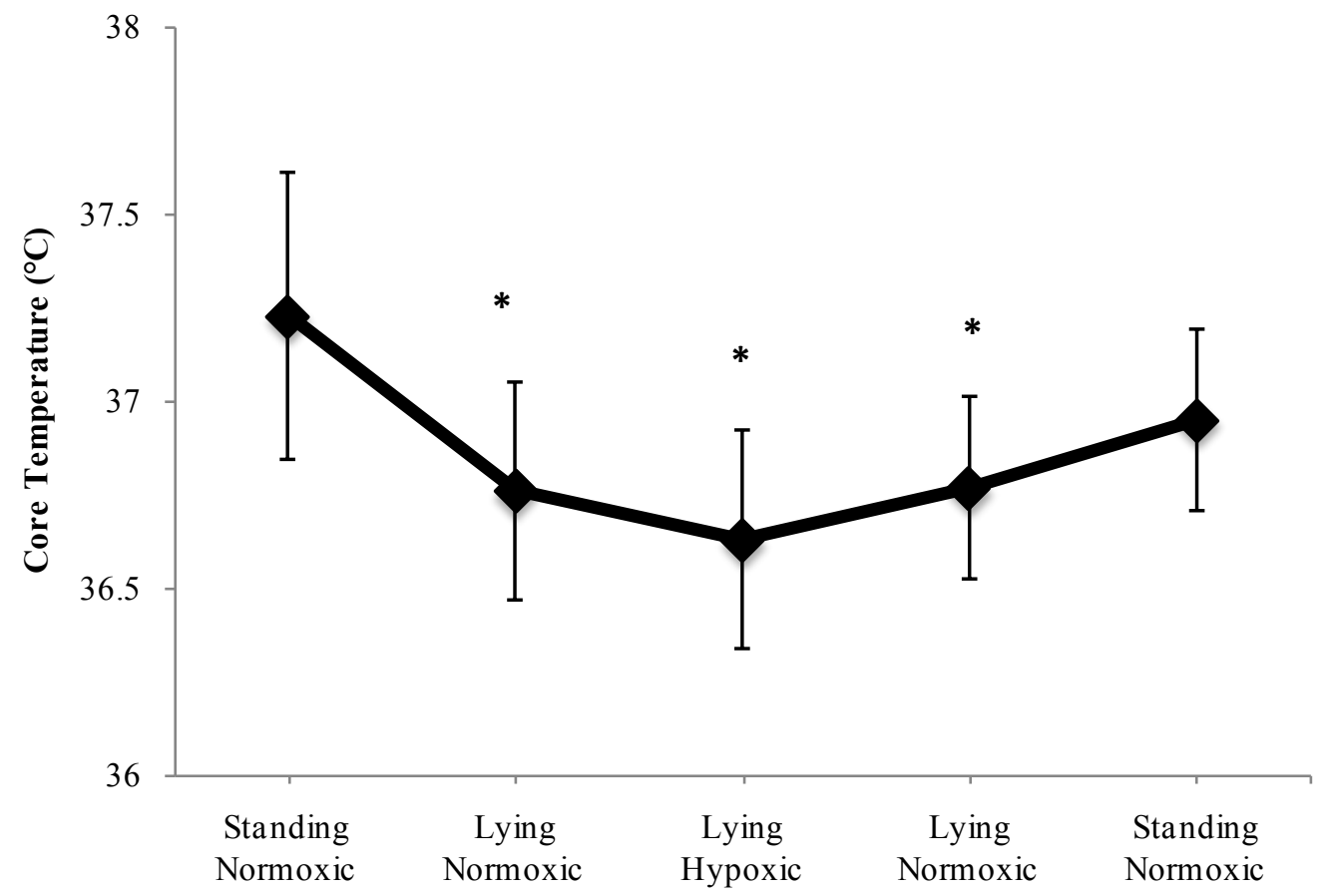

Figure 1. Mean $\pm \mathrm{SD}$ core temperat ure the in five different conditions: standing normoxic $\left(20.9 \% \mathrm{O}_{2}\right)$, lying normoxic $\left(20.9 \% \mathrm{O}_{2}\right)$, lying hypoxic $(12-15 \%$ $\left.\mathrm{O}_{2}\right)$, lying normoxic $\left(20.9 \% \mathrm{O}_{2}\right)$, standing normoxic $\left(20.9 \% \mathrm{O}_{2}\right) *$ denotes significant difference from standing normoxic environment $(\mathrm{p}<0.01)$ 


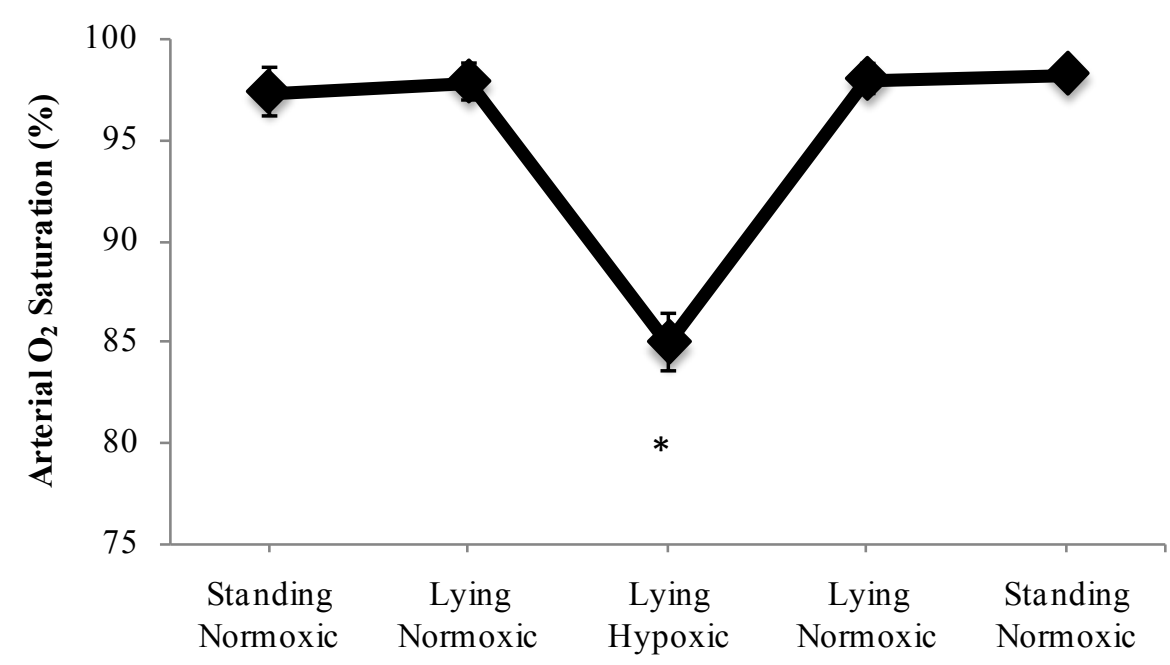

Figure 2. Mean $\pm \mathrm{SD}$ arterial $\mathrm{O}_{2}$ sat uration in the five different conditions: standing normoxic $\left(20.9 \% \mathrm{O}_{2}\right)$, lying normoxic $\left(20.9 \% \mathrm{O}_{2}\right)$, lying hypoxic $\left(12-15 \% \mathrm{O}_{2}\right)$, lying normoxic $\left(20.9 \% \mathrm{O}_{2}\right)$, standing normoxic $\left(20.9 \% \mathrm{O}_{2}\right) *$ denotes significant difference from standing normoxic environment $(\mathrm{p}<0.01)$

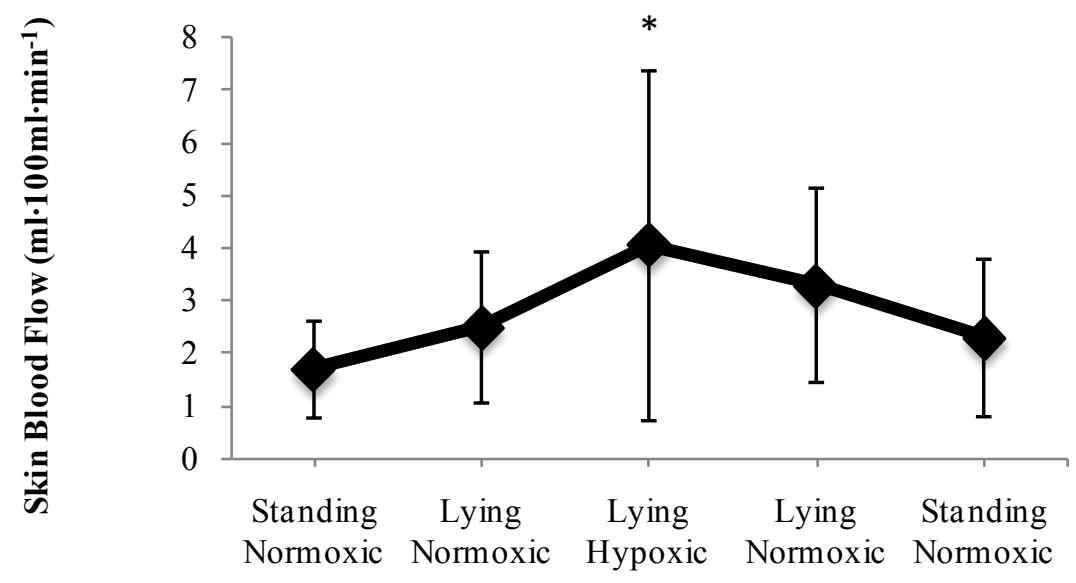

Figure 3. Mean \pm SD skin blood flow in the five different conditions: standing normoxic ( $\left.20.9 \% \mathrm{O}_{2}\right)$, lying normoxic $\left(20.9 \% \mathrm{O}_{2}\right)$, lying hypoxic $(12-15 \%$ $\left.\mathrm{O}_{2}\right)$, lying normoxic $\left(20.9 \% \mathrm{O}_{2}\right)$, standing normoxic $\left(20.9 \% \mathrm{O}_{2}\right) *$ denotes significant difference from standing normoxic and lying normoxic conditions $(\mathrm{p}$ $<0.01$ )

As seen in Fig. 3, a significant effect on skin blood flow was also found $\left(\mathrm{F}_{(4,36)}=3.57, \mathrm{p}<0.01\right)$ between the five different testing conditions. Specially, there was a significant $(p<0.05)$ difference in skin blood flow between the initial standing normo xic environment $\left(1.7 \pm 0.9 \mathrm{ml} \cdot 100 \mathrm{ml} \cdot \mathrm{min}^{-1}\right)$ and the lying hypoxic environment $(4.1 \pm 3.3 \mathrm{ml} \cdot 100 \mathrm{ml} \cdot \mathrm{min}$ $\left.{ }^{-1}\right)$. However, there was no statistically significant $(p>0.05)$ difference between the other three conditions. There also was a significant inverse correlation $(r=-0.50, \mathrm{p}<0.01)$ between skin blood flow and core body temperature across all five conditions.

\section{Discussions}

\subsection{Posture, not Acute Hypoxia, Decreases Core Temper ature}

The most important finding in the current study was that changes in posture, not acute hypoxia, caused a significant decrease in core temperature. This is evidenced by the fact that the subjects had a significant $0.4^{\circ} \mathrm{C}$ decrease in core temperature when posture changed from standing to lying. However, after the core temperature stabilized following the posture change the introduction of hypoxia had no further effect. Previous studies that proposed acute hypoxia to decrease core temperature also found a $0.4^{\circ} \mathrm{C}$ decrease, although, the methods used in these studies did not control for posture $[1,2,5]$. Subjects in these studies transitioned from standing to lying when exposed to hypoxia. Thus, it is 
reasonable to hypothesize that the decrease in core temperature they attributed to acute hypoxia could have, at least in part, been attributable to changes in posture.

Two previous studies support the current finding that acute hypoxia does not significantly decrease core temperature. Wezler and Frank found no significant difference in core temperature when subjects were exposed to either a $20.8 \%$ or $12 \%$ oxygen environment[6].Likewise, Nair and George reported no change in body temperature with in 24 hours after subjects were flown to an altitude of 3, $300 \mathrm{~m}$ [7].

Such findings, coupled with the results of the current study, suggest that core temperature can be significantly changed by posture, but not acute hypoxia. This statement is supported by results of Cranston et al.[4]. They found that there was approximately a $0.4{ }^{\circ} \mathrm{C}$ decrease in core temperature when subjects changed posture from standing to lying. Conversely, when subjects went from a lying to standing position, core temperature rose to near the initial standing level. Such results agree with the findings of the current study. It has been suggested that the changes in core temperature associated with posture are related to circulatory readjustments. There is an increased return of cool venous blood from the legs to the core when lying down. Conversely, upon standing there is a decreased return of venous blood and a reduction of heat loss from the legs due to cutaneous vasoconstriction[4].

\subsection{Skin Blood Flow Res ponse}

It has been previously been hypothesized that core temperature can be affected by alterations in skin blood flow[2]. The results of the current study support this as a significant inverse correlation $(r=-0.50, p<0.01)$ was found between core temperature and skin blood flow across the five conditions. It seems reasonable to hypothesize that increasing skin blood flow in a thermoneutral environment increases heat loss to the environment via radiation, conduction, and convection, and thus, lowers core temperature.

\subsection{Variability in Hypoxic Res ponse}

Interestingly, there was a large inter-subject variability in the subjects' response to the hypoxic environment. Specifically, hemoglobin $\mathrm{O}_{2}$ saturation was monitored and maintained at $85 \%$ throughout the hypoxic exposure for all subjects, however, the inspired oxygen concentration needed to accomplish this ranged from $12-15 \%$. Thus, it seems reas onable to hypothesize that past studies that used only one hypoxic oxygen concentration for all subjects must have had a large degree of variability in the hemoglobin oxygen saturation.

\section{Conclusions}

In conclusion, the results of the current study showed that mean core body temperature significantly $(\mathrm{p}<0.05)$ decreased by $0.4^{\circ} \mathrm{C}$ when the subjects transitioned from a standing to lying position. However, acute hypoxia, which reduced the mean oxygen saturation to $85 \%$, did not significantly affect core temperature. Such results suggest that when posture is controlled, acute hypoxia does not significantly decrease core body temperature. Thus, the results of previous studies that have reported decreases in core temperature with acute hypoxia, but failed to control for posture, need to be questioned.

\section{REFERENCES}

[1] Kottke FJ, Phalen JS, Taylor CB, Visscher MB, Evans GT (1947) Effect of hyp oxia up on temperature regulation of mice, dogs, and man. Am J Physiol 153:10-15.

[2] Robinson KA, Haymes EM (1990) Metabolic effects of exposure to hypoxia plus cold at rest and during exercise in humans. J ApplPhysiol, 69(2):720-725.

[3] Rabinowitz RP, Cookson ST, Wasserman SS, Mackowiak PA (1990) Effects of anatomic site, oral stimulation and body position on estimates of body temperature. Arch Intern Med 156:777-780.

[4] Cranston WI, Gerbrandy J, Snell ES (1954) Oral, rectal and oesophageal temperatures and some factors affecting them. J ApplPhysiol 126:347-358.

[5] Wagner JA, Robinson S, Marino RP (1974) Age and temperature regulation of humans in neutral and cold environments. J App1 Physiol. 37(4):562-565.

[6] Wezler K, Frank E (1948) ChemischeWärmeregulationgege nKälte und Hitze in Sau erstoffmangel. Pflüger's Arch Physiol 250:439-469.

[7] Nair CS, George S (1972) The effect of altitude and cold on body temperature during acclimatization of man at $3,300 \mathrm{~m}$. Int J Biometerol 16(1):79-84. 